\title{
Simple and accurate correlation of experimental redox potentials and DFT- calculated HOMO/LUMO energies of polycyclic aromatic hydrocarbons.
}

Dalvin D. Méndez-Hernández, Pilarisetty Tarakeshwar, Devens Gust, Thomas A. Moore, Ana L. Moore and Vladimiro Mujica

Department of Chemistry and Biochemistry, Arizona State University, Tempe, Arizona 85287-1604

E-mail: ddmendez@asu.edu; tpilaris@asu.edu; gust@asu.edu, tmoore@asu.edu, amoore@asu.edu; vmujica@asu.edu

\begin{abstract}
The ability to accurately predict the oxidation and reduction potentials of molecules is very useful in various fields and applications. Quantum mechanical calculations can be used to access this information, yet sometimes the usefulness of these calculations can be limited because of the computational requirements for large systems. Methodologies that yield strong linear correlations between calculations and experimental data have been reported, however the balance between accuracy and computational cost is always a major issue. In this work, linear correlations (with an $\mathrm{R}^{2}$ value of up to 0.9990) between DFT-calculated HOMO/LUMO energies and seventy redox potentials from a series of fifty-one polycyclic aromatic hydrocarbons (obtained from the literature) are presented. The results are compared to previously reported linear correlations that were obtained with a more expensive computational methodology based on a Born-Haber thermodynamic cycle. It is shown in this article that similar or better correlations can be obtained with a simple and cheaper calculation.
\end{abstract}

\section{Keywords: HOMO, LUMO, reduction, oxidation, linear correlation}

\section{Introduction}

Determination of the reduction and oxidation potentials of a given molecule at an interface is important in many research areas such as dye sensitized solar cells (DSSC), organic photovoltaics (OPV), and artificial photosynthesis, where tuning the thermodynamic properties of every component of a system is essential for it to work in 
the desired way [1-6]. The perturbation of the HOMO and LUMO energies (HLE) is also of interest in the context of designing both novel and efficient molecules for harnessing solar energy in artificial photosynthesis and photocatalysis [3-6]. Ideally one would like to know with accuracy the redox properties of a compound of interest before embarking on an often difficult, expensive and time-consuming synthetic procedure.

The simplest way to rationalize an approximate linear relationship between HLE and oxidation/reduction potentials is to consider the Marcus Relation for interfacial electron transfer

$\Delta G^{\#}=\frac{\left(\Delta_{r} G^{0}+\lambda\right)^{2}}{4 \lambda}$

where $\Delta G^{\#}$ is the free energy of activation and $\Delta_{r} G^{o}$ and $\lambda$ are the reaction free energy and the total reorganization energy, respectively. Solving for $\Delta_{r} G^{0}$ in equation (1) gives

$\Delta_{r} G^{0}=\sqrt{4 \lambda \Delta G^{\#}}-\lambda$

Further we introduced the thermodynamic relation between $\Delta_{r} G^{o}$ and the electrochemical cell potential

$\Delta_{r} G^{0}=-n F\left(E-E^{0}\right)$

The reorganization energy is generally decomposed into two contributions, $\lambda_{i}$ and $\lambda_{0}$, coming from the molecule and from the solvent, respectively

$\lambda=\lambda_{i}+\lambda_{o}$

This decomposition leads to the following equation 


$$
\Delta_{r} G^{0}=\sqrt{4\left(\lambda_{i}+\lambda_{o}\right) \Delta G^{\#}}-\lambda_{o}-\lambda_{i}
$$

Up to this point equation (5) is formally exact. To proceed, one has to invoke that in many reactions $\lambda_{i}=\lambda_{o}[7]$ and that the first two terms in (5) are approximately constant within a family of chemically related molecules, while $\lambda_{i}$ is proportional to the energy of the HOMO or the LUMO depending on whether oxidation or reduction is considered [8]. Combining these two approximations and using equations (3) and (5) leads to the linear relationship

$E_{\text {OX/RED }}=a+b \varepsilon_{\text {HOMO/LUMO }}$

where $E_{\text {OX/RED }}$ is the experimental redox potentials, $\varepsilon_{\text {HОMO/LUMO }}$ the calculated HLE, and $a$ and $b$ are constants.

Maccoll showed for the first time in 1949 that a good correlation could be obtained between Huckel LUMO energies and experimental reduction potentials [9]. Nevertheless, in the computational electrochemistry literature [10-12], efforts to predict redox potentials steer away from this methodology mainly because of the assumptions involved (e.g. molecular and solvent reorganization energies are not included in the calculation). Instead, a Born-Haber thermodynamic cycle is preferred as the free energies are directly calculated and solvation energies are accounted for, which are significant as has been observed when electrochemistry is done under different solvents and conditions [13]. Unfortunately, the main drawback for this methodology is that when applied to large molecules (e.g. polycyclic aromatic hydrocarbons (PAHs), porphyrins, phthalocyanines) the computations are very expensive.

To resolve this issue, Fry et al. have reported a methodology that accurately predicts the redox potentials of PAHs with a simplified approach to the Born-Haber thermodynamic cycle [14]. This methodology involves the optimization of molecules in both the ground state and the reduced or oxidized state (radical anion or radical cation respectively) with a 
continuum based solvent model in order to account for reorganization energies. This approach removes the optimization step in the gas phase that is part of the Born-Haber thermodynamic cycle, thus decreasing the number of calculations, from six to three (in order to obtain both oxidation and reduction potentials). This methodology was tested with fifty-one PAHs, whose experimental redox potentials (which were obtained from the literature) were measured under similar conditions. They were able to obtain a very strong correlation, up to $\mathrm{R}^{2}=0.9981$, between the calculated and the experimental values.

Before Fry, in 2008, Gillmore et al. introduced a further simplified methodology. It consists of a molecular energy optimization in gas phase, followed by a single point calculation in the presence of a continuum solvent model [15]. This increases again the number of calculations to six (in order to obtain both oxidation and reduction potentials), but the computational time is reduced because four of them (the ones that involve the solvent) are single point calculations. They found a very good correlation between the calculated energy difference and the reduction potentials of quinones, cyanoaromatics and N-metyl heteroaromatic cations [15], and later expanded their methodology to PAHs, flexible aromatic molecules and heterocyclic amines [16].

In searching for a methodology to calculated redox potentials accurately and that is computationally less expensive than Gillmore's approach but at least as accurate as Fry's, reported herein is a good correlation between HLE (calculated at the DFT level using the B3LYP/6-31G(d) functional) and experimental redox potentials. This follows Maccoll's methodology and significantly reduces the complexity of the required calculations. The advantage of this approach is that just one optimization calculation is required, thus it can be applied to large molecules with a relatively low computational cost.

\section{Computational method}

To test this methodology and compare it to previously reported correlations, the library of PAHs collected by Fry et al. [14], which include data from six different references, was used. The literature redox potentials were measured in acetonitrile and are reported in V vs. ferrocene/ferrocenium $\left(\mathrm{Fc} / \mathrm{Fc}^{+}\right)$, which was used as an internal reference. 
All PAHs were optimized using Gaussian 09 [17] at the B3LYP/6-31G(d) level of theory [18-23] in the gas phase and in the presence of acetonitrile simulated using the Conductor-like Polarizable Continuum Model (CPCM) [24-25]. The calculated HLE were plotted against the experimental oxidation and reduction potentials respectively.

\section{Results}

Plots for the calculated HLE of a series of fifty-one PAHs against their experimental oxidation and reduction potentials are shown in Figure 1 and 2. When using acetonitrile as the solvent a very strong correlation $\left(\mathrm{R}^{2}=0.9989\right)$ is observed between the calculated and experimental values. It is noteworthy that there is also a very strong correlation between HLE and redox potentials when the molecules are optimized in the gas phase $\left(\mathrm{R}^{2}=0.9990\right)$. The reason why this is true in this specific case is because solvent reorganization energies are very similar for the set of PAHs under study, resulting in a cancelation of the error obtained by not including the solvent in the calculation. A summary of the results obtained from the method used in this work as well as the results obtained by Fry et al. can be found in Table 1.

The correlations obtained with the method used in this paper are comparable or better than the ones obtained by Fry. When analyzing the oxidation and reduction potentials together Fry obtained a mean absolute deviation (MAD) of $0.056 \mathrm{~V}$ while we get a MAD of $0.046 \mathrm{~V}$. When the data is split in two sets (only reduction or oxidation potentials), Fry's correlation is better than ours for both reductions and oxidations, but the error is of the same order of magnitude for both approaches. In general, both methods are in very good agreement with the experimental values, our method having the advantage that it consists of only one optimization rather than three. 


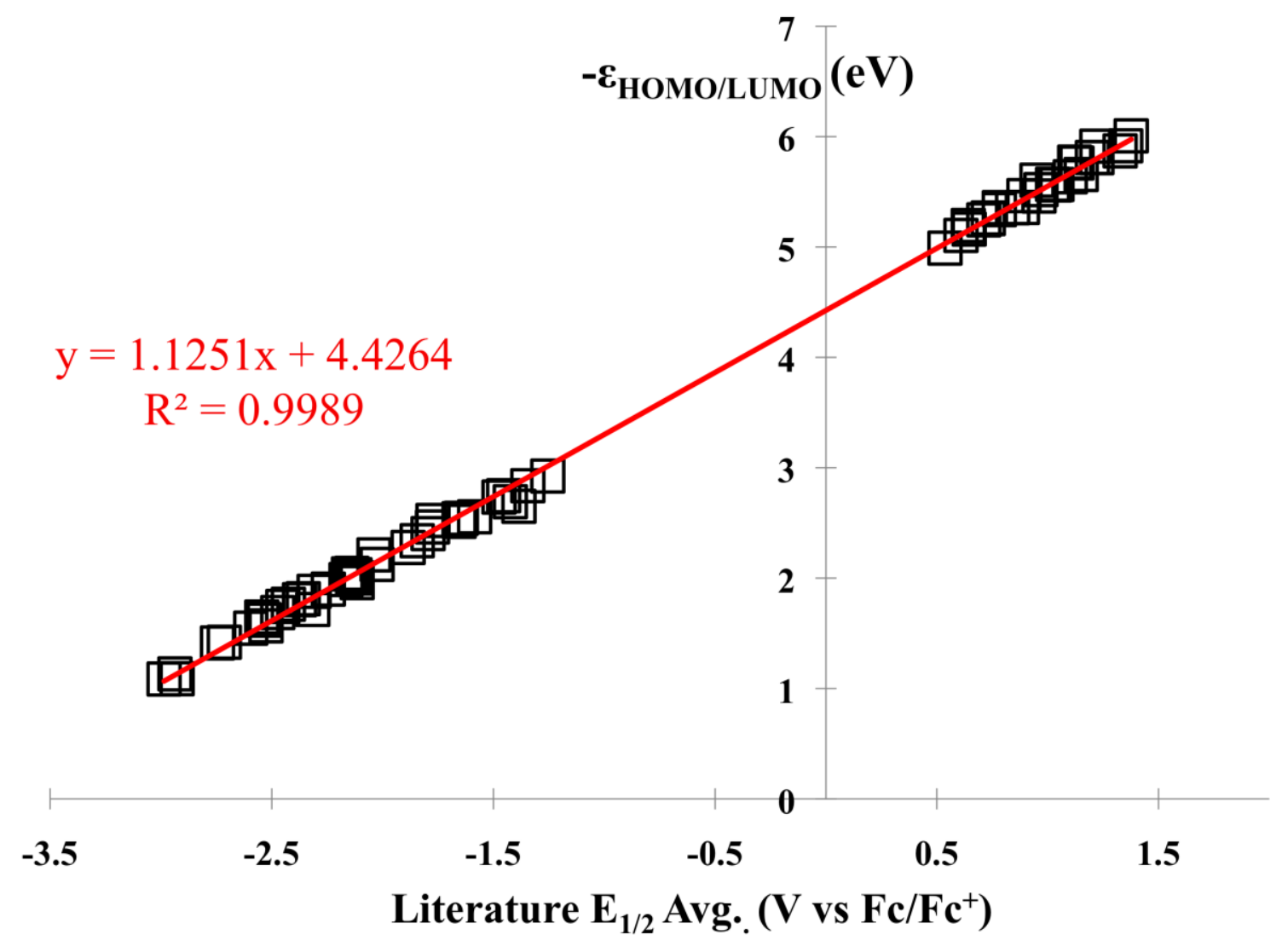

Fig. 1 Plot of computed HOMO/LUMO energies (eV) using acetonitrile as the solvent vs. experimental $E_{1 / 2}$ avg. obtained from [14] and references therein. 


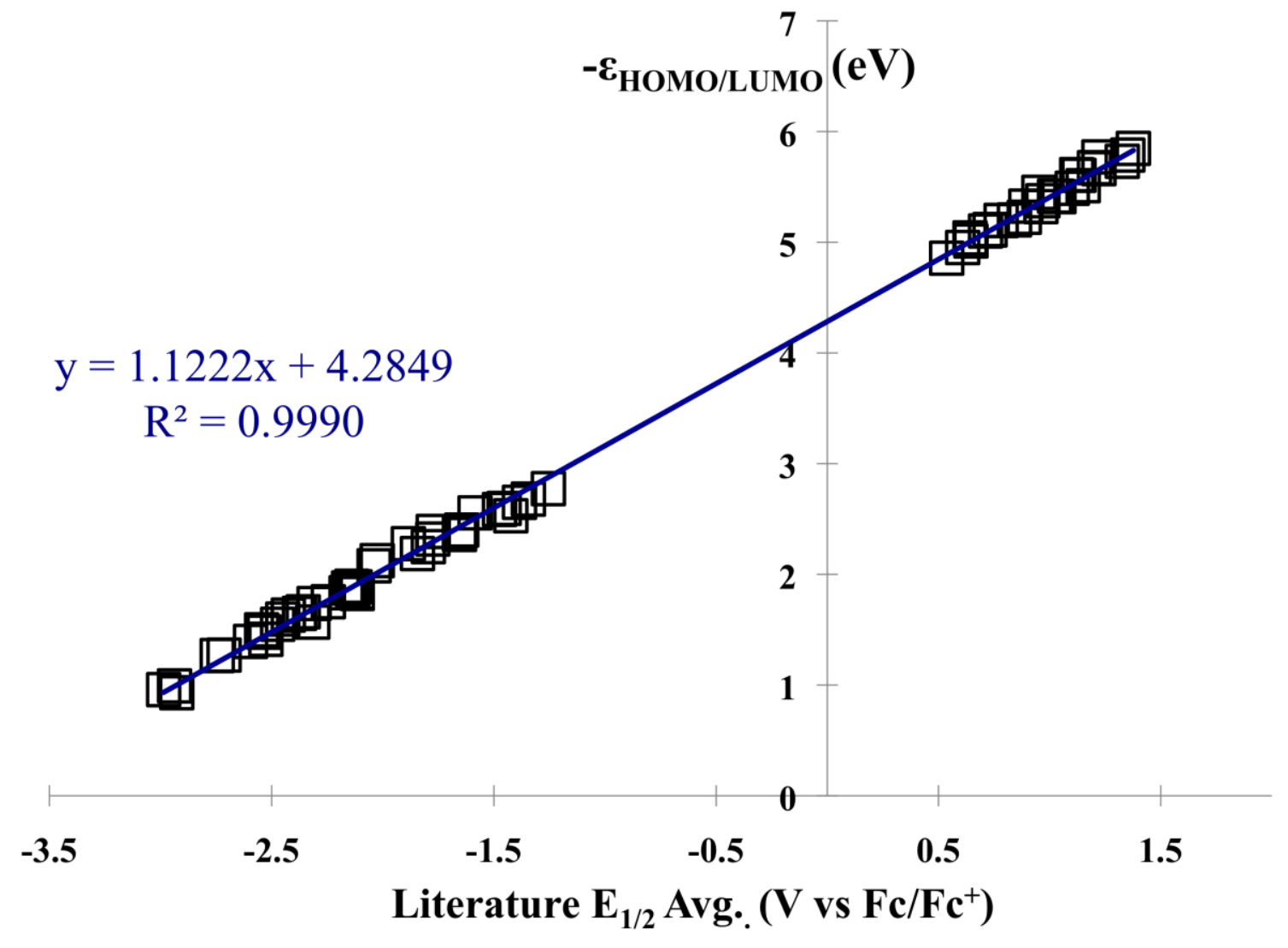

Fig. 2 Plot of computed HOMO/LUMO energies $(\mathrm{eV})$ in the gas phase vs. experimental $\mathrm{E}_{1 / 2}$ avg. obtained from [14] and references therein.

\begin{tabular}{|c|c|c|c|c|c|c|c|}
\hline \multirow{2}{*}{$\begin{array}{l}\text { This work } \\
\text { acetonitrile }\end{array}$} & \multirow[b]{2}{*}{ All } & slope $(\mathrm{eV} / \mathrm{V})$ & $y$-intercept $(\mathrm{eV})$ & $\mathbf{R}^{2}$ & MAD (V) & $\operatorname{RMSD}^{\mathbf{a}}(\mathbf{V})$ & $x$-intercept ${ }^{b}(V)$ \\
\hline & & 1.1251 & 4.4264 & 0.9989 & 0.046 & 0.058 & -3.93 \\
\hline \multirow{5}{*}{ gas phase } & Oxidation & 1.1288 & 4.4311 & 0.9700 & 0.037 & 0.047 & -3.93 \\
\hline & Reduction & 1.0444 & 4.2499 & 0.9882 & 0.039 & 0.053 & -4.07 \\
\hline & All & 1.1222 & 4.2849 & 0.9990 & 0.046 & 0.056 & -3.82 \\
\hline & \multirow{2}{*}{$\begin{array}{l}\text { Oxidation } \\
\text { Reduction }\end{array}$} & 1.1318 & 4.2813 & 0.9740 & 0.035 & 0.043 & -3.78 \\
\hline & & 1.0658 & 4.1616 & 0.9864 & 0.044 & 0.058 & -3.90 \\
\hline \multicolumn{8}{|l|}{ Reference [14] } \\
\hline & All & 0.8591 & 4.442 & 0.9981 & 0.056 & --- & -5.17 \\
\hline & \multirow{2}{*}{$\begin{array}{l}\text { Oxidation } \\
\text { Reduction }\end{array}$} & 1.073 & 4.227 & 0.9847 & 0.032 & --- & -3.94 \\
\hline & & 0.947 & 4.64 & 0.9924 & 0.023 & --- & -4.90 \\
\hline
\end{tabular}


Table 1. Summary of the results from the linear correlations. a) Root-mean-square deviation b) calculated with $\mathrm{x}$-intercept $=-b / a$.

\section{Conclusions}

A very strong linear correlation of DFT-calculated HLE and redox potentials of PAHs is shown. It is important to emphasize that only one optimization calculation per molecule is required to obtain both HLEs. In contrast, at least three (and up to six) optimizations per molecule are required to obtain a theoretical approximation of the potentials by the other methods described above. This can be a powerful tool to use when one needs to quickly and accurately predict oxidation and reduction potentials of new compounds given that one have a series of similar compounds whose redox potential are already known.

The strong correlation obtained from HLE and redox potentials of PAHs was independent of whether the solvent model was included in the calculations. This may not be the case when including in the correlation other groups of molecules that have different solvent reorganization energies. For future work this methodology will be extended to quinones, cyanoaromatics, porphyrins, phthalocyanines and perylenes.

\section{Acknowledgements}

We would like to thank Dr. Jason G. Gillmore for very useful discussions and suggestions. Thanks as well to John J. Tomlin for his suggestions, and all the members of the Gust-Moore-Moore research group for inspirational conversations.

DDMH is supported by the National Science Foundation Graduate Research Fellowship Program (NSF-GRFP) under Grant No. DGE-0802261 and by the More Graduate Education at Mountain States Alliance (MGE@MSA) Alliance for Graduate Education and the Professoriate (AGEP) National Science Foundation (NSF) Cooperative Agreement No. HRD-0450137.

This work was supported as part of the Center for Bio-Inspired Solar Fuel Production, an Energy Frontier Research Center funded by the U.S. Department of Energy, Office of Science, Office of Basic Energy Sciences under Award Number DE-SC0001016. 
Calculations were performed using the ASU Advance Computer Center Saguaro system.

\section{References}

1. Hagberg DP, Marinado T, Karlsson KM, Nonomura K, Qin P, Boschloo G, Brinck T, Hagfeldt A, Sun L (2007) Tuning the HOMO and LUMO Energy Levels of Organic Chromophores for Dye Sensitized Solar Cells. J. Org. Chem. 72:9550-9556. doi: 10.1021/jo701592x

2. Hagberg DP, Yum JH, Lee H, De Angelis F, Marinado T, Karlsson KM, Humphry-Baker R, Sun L, Hagfeldt A, Grätzel M, Nazeeruddin MdK (2008) Molecular Engineering of Organic Sensitizers for Dye-Sensitized Solar Cell Applications. J. Am. Chem. Soc. 130:6259-6266. doi: $10.1021 / \mathrm{ja} 800066 \mathrm{y}$

3. Scharber MC, Mühlbacher D, Koppe M, Denk P, Waldauf C, Heeger AJ, Brabec CJ (2006) Design Rules for Donors in Bulk-Heterojunction Solar Cells-Towards $10 \%$ Energy-Conversion Efficiency. Adv. Mater. 18:789-794. doi: 10.1002/adma.200501717

4. Gust D, Moore TA, Moore AL (2001) Mimicking Photosynthetic Solar Energy Transduction. Acc. Chem. Res. 34:40-48. doi: 10.1021/ar9801301

5. Lee C, Lu H, Lan, Huang Y, Liang Y, Yen W, Liu Y, Lin Y, Diau EW, Yeh C (2009) Novel Zinc Porphyrin Sensitizers for Dye-Sensitized Solar Cells: Synthesis and Spectral, Electrochemical, and Photovoltaic Properties. Chem. Eur. J. 15:1403-1412. doi: 10.1002/chem.200801572

6. Meisner JS, Sedbrook DF, Krikorian M, Chen J, Sattler A, Carnes ME, Murray CB, Steigerwald M, Nuckolls C (2012) Functionalizing molecular wires: a tunable class of $\alpha, \omega$-diphenyl- $\mu, v$ dicyano-oligoenes. Chem. Sci. 3:1007-1014. doi: 10.1039/C2SC00770C

7. Previtali CM (1995) Solvent effects on intermolecular electron transfer processes. Pure \& Appl. Chern, 67(1):127-134. doi: 10.1351/pac199567010127.

8. Lowe JP (1993) Quantum Chemistry, Second Edition. Academic Press. pp 273-275

9. Maccoll, A. (1949) Reduction Potentials of Conjugated Systems. Nature 163:178-179. doi: $10.1038 / 163178 \mathrm{a} 0$

10. Winget P, Weber EJ, Cramer CJ, Truhlar DG (2000) Computational electrochemistry: aqueous one-electron oxidation potentials for substituted anilines. Phys. Chem. Chem. Phys. 2:1231-1239. doi: 10.1039/A909076B

11. Baik M, Friesner RA (2002) Computing Redox Potentials in Solution: Density Functional Theory as A Tool for Rational Design of Redox Agents. J. Phys. Chem. A 106:7407-7412. doi: $10.1021 / j p 025853 n$

12. Schmidt am Busch M, Knapp EW (2005) One-Electron Reduction Potential for Oxygen- and Sulfur-Centered Organic Radicals in Protic and Aprotic Solvents. J. Am. Chem. Soc. 127:1573015737. doi: 10.1021/ja0526923 
13. Cardona CM, Li W, Kaifer AE, Stockdale D, and Bazan GC (2011) Electrochemical Considerations for Determining Absolute Frontier Orbital Energy Levels of Conjugated Polymers for Solar Cell Applications. Adv. Mater. 23:2367-2371. doi: 10.1002/adma.201004554

14. Davis AP and Fry AJ (2010) Experimental and Computed Absolute Redox Potentials of Polycyclic Aromatic Hydrocarbons are Highly Linearly Correlated Over a Wide Range of Structures and Potentials. J. Phys. Chem. A 114:12299-12304. doi: 10.1021/jp106088n

15. Speelman AL and Gillmore JG (2008) Efficient Computational Methods for Accurately Predicting Reduction Potentials of Organic Molecules. J. Phys. Chem. A 112:5684-5690. doi: 10.1021/jp800782e

16. Lynch AJ, Speelman AL, Curry BA, Murillo CS, and Gillmore JG (2012) Expanding and Testing a Computational Method for Predicting the Ground State Reduction Potentials of Organic Molecules on the Basis of Empirical Correlation to Experiment. J. Org. Chem. 77 (15):64236430. doi: 10.1021/jo300853k

17. Frisch MJ, Trucks GW, Schlegel HB, Scuseria GE, Robb MA, Cheeseman JR, Scalmani G, Barone V, Mennucci B, Petersson GA, Nakatsuji H, Caricato M, Li X, Hratchian HP, Izmaylov A. F, Bloino J, Zheng G, Sonnenberg JL, Hada M, Ehara M, Toyota K, Fukuda R, Hasegawa J, Ishida M, Nakajima T, Honda Y, Kitao O, Nakai H, Vreven T, Montgomery Jr. JA, Peralta JE, Ogliaro F, Bearpark M, Heyd JJ, Brothers E, Kudin KN, Staroverov VN, Kobayashi R, Normand J, Raghavachari K, Rendell A, Burant JC, Iyengar SS, Tomasi J, Cossi M, Rega N, Millam JM, Klene M, Knox JE, Cross JB, Bakken V, Adamo C, Jaramillo J, Gomperts R, Stratmann RE, Yazyev O, Austin AJ, Cammi R, Pomelli C, Ochterski JW, Martin RL, Morokuma K, Zakrzewski VG, Voth GA, Salvador P, Dannenberg JJ, Dapprich S, Daniels AD, Farkas Ö, Foresman JB, Ortiz JV, Cioslowski J, Fox DJ (2009) Gaussian 09, Revision A.02; Gaussian, Inc., Wallingford, CT

18. Lee C, Yang W, Parr RG (1988) Development of the Colle-Salvetti correlation-energy formula into a functional of the electron density. Phys. Rev. B 37:785-789. doi: 10.1103/PhysRevB.37.785

19. Becke AD (1988) Density-functional exchange-energy approximation with correct asymptotic behavior. Phys. Rev. A 38:3098-30100. doi: 10.1103/PhysRevA.38.3098

20. Becke AD (1996) Densityfunctional thermochemistry. IV. A new dynamical correlation functional and implications for exactexchange mixing. J. Chem. Phys. 104:1040-1046. doi: $10.1063 / 1.470829$

21. Francl MM, Pietro WJ, Hehre WJ, Binkley JS, Gordon MS, DeFree DJ, Pople, JA (1982) Selfeonsistent molecular orbital methods. XXIII. A polarizationtype basis set for secondrow elements. J. Chem. Phys. 77:3654-3665. doi: 10.1063/1.444267 
22. Harihan PC, Pople JA (1973) The influence of polarization functions on molecular orbital hydrogenation energies. Theor. Chim. Acta 28:213-222. doi: 10.1007/BF00533485.

23. Rassalov V, Pople JA, Ratner M, Windus TL (1998) 6-31G* basis set for atoms K through Zn. J. Chem. Phys. 109:1223-1229. doi: 10.1063/1.476673

24. Barone V, Cossi M (1998) Quantum Calculation of Molecular Energies and Energy Gradients in Solution by a Conductor Solvent Model. Journal of Physical Chemistry A 102:1995-2001. doi: 10.1021/jp9716997

25. Cossi M, Rega N, Scalmani G, Barone V (2003) Energies, structures, and electronic properties of molecules in solution with the C-PCM solvation model. Journal of Computational Chemistry 24:669-681. doi: 10.1002/jcc.10189 